\title{
UTILIZAÇÃO DO CLORETO DE DIALQUIL CARBAMOIL NA PREVENÇÃO E TRATAMENTO DE BIOFILME EM FERIDAS
}

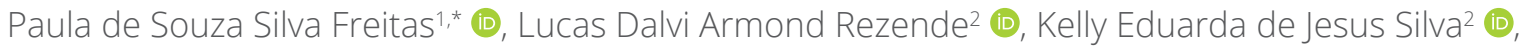

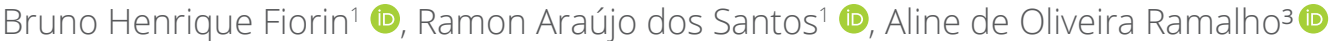

\section{RESUMO}

Objetivos: Objetivou-se identificar os benefícios na utilização do Cloreto de Dialquil Carbamoil para tratamento de biofilmes em feridas. Métodos: Trata-se de uma revisão integrativa de literatura que visou responder à questão norteadora: "Quais os benefícios do uso de Cloreto de Dialquil Carbamoil na cicatrização de lesões de pele?". As etapas de seleção dos artigos resultaram em 13 artigos inclusos. Resultados: Os artigos selecionados foram agrupados em dois grupos, a saber: prevenção e tratamento de infecção em feridas e prevenção de infecção de sítio cirúrgico, sendo nove produções no primeiro grupo e quatro no segundo. Os estudos demonstraram que o Cloreto de Dialquil Carbamoil atenua os sintomas de colonização, como odor, queixas álgicas e exsudação, além disso, auxilia no gerenciamento profilático do biofilme da ferida. As evidências apontam que coberturas com Cloreto de Dialquil Carbamoil não possuem efeitos adversos, tornando-se opções viáveis e seguras para lesões crônicas, agudas e, principalmente, infectadas. Conclusão: Identificou-se que o Cloreto de Dialquil Carbamoil foi capaz de promover ações benéficas ao tratamento de feridas, especialmente as de maior complexidade. A escolha adequada das coberturas e dos curativos pode contribuir com a utilização racional das tecnologias existentes e dos antimicrobianos, culminando em redução de custos e promoção de qualidade de vida aos indivíduos com feridas crônicas.

DESCRITORES: Cicatrização. Ferimentos e lesões. Controle de infecções. Estomaterapia.

\section{USE OF DIALKYL CARBAMOYL CHLORIDE IN THE PREVENTION AND TREATMENT OF BIOFILM IN WOUNDS}

\begin{abstract}
Objectives: The aim was to identify the benefits of using Dialkyl Carbamoyl Chloride for the treatment of biofilms in wounds. Methods: This is an integrative literature review that aimed to answer the guiding question: "What are the benefits of using Dialkyl Carbamoyl Chloride in the healing of skin lesions?". The article selection stages resulted in 13 articles included. Results: The selected articles were grouped into two groups, namely: prevention and treatment of infection in wounds and prevention of surgical site infection, with nine productions in the first group and four in the second. Studies have shown that Dialkyl Carbamoyl Chloride attenuates colonization symptoms, such as odor, pain complaints and oozing, in addition to aiding in the prophylactic management of wound biofilm. Evidence indicates that dressings with Dialkyl Carbamoyl Chloride have no adverse effects, making them viable and safe options for chronic, acute and, mainly, infected injuries. Conclusion: It was identified that
\end{abstract}

1. Universidade Federal do Espírito Santo - Programa de Pós-graduação em Enfermagem - Vitória (ES), Brasil.

2. Universidade Federal do Espírito Santo - Centro de Ciências da Saúde - Departamento de Enfermagem - Vitória (ES), Brasil.

3. Universidade de São Paulo - Escola de Enfermagem - Hospital Sírio Libanês - São Paulo (SP), Brasil.

*Autora correspondente: paulassfreitas@gmail.com

Editor de Seção: Manuela M F Coelho

Recebido: Abr. 2021, 23 | Aceito: Jun. 2021, 23

Como citar: Freitas PSS; Rezende LDA; Silva KEJ; Fiorin BH; Santos RA; Ramalho AO. Utilização do Cloreto de Dialquil Carbamoil na prevenção e tratamento de biofilme em feridas. ESTIMA, Braz. J. Enterostomal Ther., 2021, 19: e1621. https://doi.org/10.30886/ estima.v19.1087_PT 
Dialkyl Carbamoyl Chloride was able to promote beneficial actions in the treatment of wounds, especially those of greater complexity. The proper choice of dressings and coverings can contribute to the rational use of existing technologies and antimicrobials, culminating in cost reduction and promotion of quality of life for individuals with chronic wounds.

DESCRIPTORS: Healing. Wounds and injuries. Infection Control. Stomatherapy.

\title{
USO DE CLORURO DE DIALQUIL CARBAMOIL EN LA PREVENCIÓN Y TRATAMIENTO DE BIOFILM EN HERIDAS
}

\begin{abstract}
RESUMEN
Objetivos: El objetivo fue identificar los beneficios del uso de Cloruro de dialquil carbamoil para tratar biopelículas en heridas. Métodos: Se trata de una revisión integradora de la literatura, cuyo objetivo es responder a la siguiente pregunta orientadora: “¿Cuáles son los beneficios del uso de Cloruro de dialquil carbamoil en la cura de lesiones cutáneas?". Los pasos para seleccionar los artículos dieron como resultado 13 artículos incluidos. Resultados: Los artículos seleccionados se agruparon en dos grupos, a saber: Prevención y tratamiento de la infección en heridas y Prevención de la infección del sitio quirúrgico, con 9 producciones en el primer grupo y 4 en el segundo. Los estudios demostraron que Cloruro de dialquil carbamoil atenúa los síntomas de la colonización, como el olor, el dolor y la exudación, además, ayuda en el manejo profiláctico de la biopelícula de la herida. La evidencia apunta a que la cobertura Cloruro de dialquil carbamoil no tiene efectos adversos, lo que la convierte en opciones viables y seguras para lesiones crónicas, agudas y principalmente infectadas. Conclusión: Se identificó que la Cloruro de dialquil carbamoil fue capaz de promover acciones beneficiosas para el tratamiento de heridas, especialmente las de mayor complejidad. La elección adecuada de cubiertas y apósitos puede contribuir al uso racional de las tecnologías y los antimicrobianos existentes, culminando en la reducción de costos y la promoción de la calidad de vida de las personas con heridas crónicas.
\end{abstract}

DESCRIPTORES: Cicatrización de Heridas. Heridas y Traumatismos. Control de infección.

\section{INTRODUÇÃO}

As feridas de difícil cicatrização são um problema de saúde pública mundial. Sabe-se que diversos fatores interferem no processo de cicatrização, devendo ser considerados, em sua avaliação, os aspectos intrínsecos e extrínsecos ao paciente. No entanto, reconhece-se que a maioria das lesões com atraso ou impedimento da cicatrização está associada à presença de biofilme ${ }^{1,2}$.

Os biofilmes microbianos são definidos como um grupo de microrganismos $(\mathrm{MO})$ envolvidos por uma matriz polimérica protetora e aderidos a uma superfície, a qual pode ser tanto biótica quanto abiótica, formados a partir de uma ou múltiplas espécies de $\mathrm{MO}^{3}$. O biofilme apresenta-se comumente no leito da ferida com tecido desvitalizado e presente no exsudato proteico de células brancas. Dentre os principais indicadores clínicos de lesões com biofilme, encontram-se lesões com endurecimento, eritema e aumento de exsudato, além de queixas álgicas relacionadas à ferida. Os biofilmes são capazes de se reconstituir em curto prazo, devido à secreção de polímeros e por componentes do hospedeiro, indicando a necessidade de limpeza regular da lesão4.

O fato do biofilme ser capaz de se reconstituir rapidamente no leito das feridas, torna-se um fator limitante para a realização de seu manejo exclusivamente através do desbridamento mecânico ${ }^{2}$. Dessa forma, recomenda-se a adoção de cuidados estruturados, que visem a remoção do biofilme já instalado no leito bem como a utilização de estratégias que impeçam nova formação desse conglomerado microbiano ${ }^{4}$.

Nesse contexto, diversas tecnologias têm sido desenvolvidas com enfoque no manejo do biofilme e de infecção nas feridas, dentre elas temos o Cloreto de Dialquil Carbamoil, também conhecido como DACC, o qual é considerado um antimicrobiano local, por possui como mecanismo farmacológico o sequestro dos microrganismos para dentro do curativo através de ligações químicas simples5. 


\section{OBJETIVO}

Objetivou-se identificar os benefícios na utilização do DACC para tratamento de biofilmes em feridas.

\section{MÉTODO}

Trata-se de uma revisão integrativa de literatura, seguindo os seis principais passos para sua elaboração, sendo: síntese da temática a ser estudada, concretização dos critérios de inclusão e exclusão, identificação dos estudos selecionados para a revisão, categorização e análise dos estudos, interpretação dos resultados e síntese da revisão .

Para a delimitação da pergunta norteadora, apropriou-se da estratégia PICO, a qual se resume em: $P$ - População (Pessoas com lesão de pele), I - Intervenção (Uso de DACC), $C$ - Comparação/Controle (Terapia convencional) e O - Outcomes/ desfecho (Cicatrização) ${ }^{7}$. Diante do exposto, essa estratégia promoveu a formulação da seguinte questão norteadora: "Quais os benefícios do uso de Cloreto de Dialquil Carbamoil na cicatrização de lesões de pele?”.

Após a definição da questão norteadora, realizou-se a busca na literatura por meio das seguintes bases de dados: Cumulative Index to Nursingand Allied (CINAHL), National Library of Medicine (PubMed) e biblioteca Cocbrane. A busca nas bases ocorreu no mês de novembro de 2020, e para a composição da estratégia de busca foram utilizados os Descritores de Ciência em Saúde/Medical Subject Headings (DECS/MeSH) nos idiomas inglês e português, separados pelo operador Booleano "AND”, sendo eles: “Wound” ("Ferimentos e lesões”), “Wound Healing”("Cicatrização”), somados à palavra-chave "Dialkylcarbamoylchloride" ("Cloreto de Dialquilcarbamoil”).

Foram definidos como critérios de inclusão para esta revisão: publicações dos últimos 10 anos (2010 a 2020), nos idiomas inglês, espanhol e português, incluindo todos os tipos de estudo e textos, disponível na íntegra ou não, sendo excluídas as produções que se repetiram nas bases de dados e aquelas que não responderam à pergunta desta pesquisa, preprints e cartas ao editor. As etapas de seleção dos artigos estão representadas na Fig. 1.

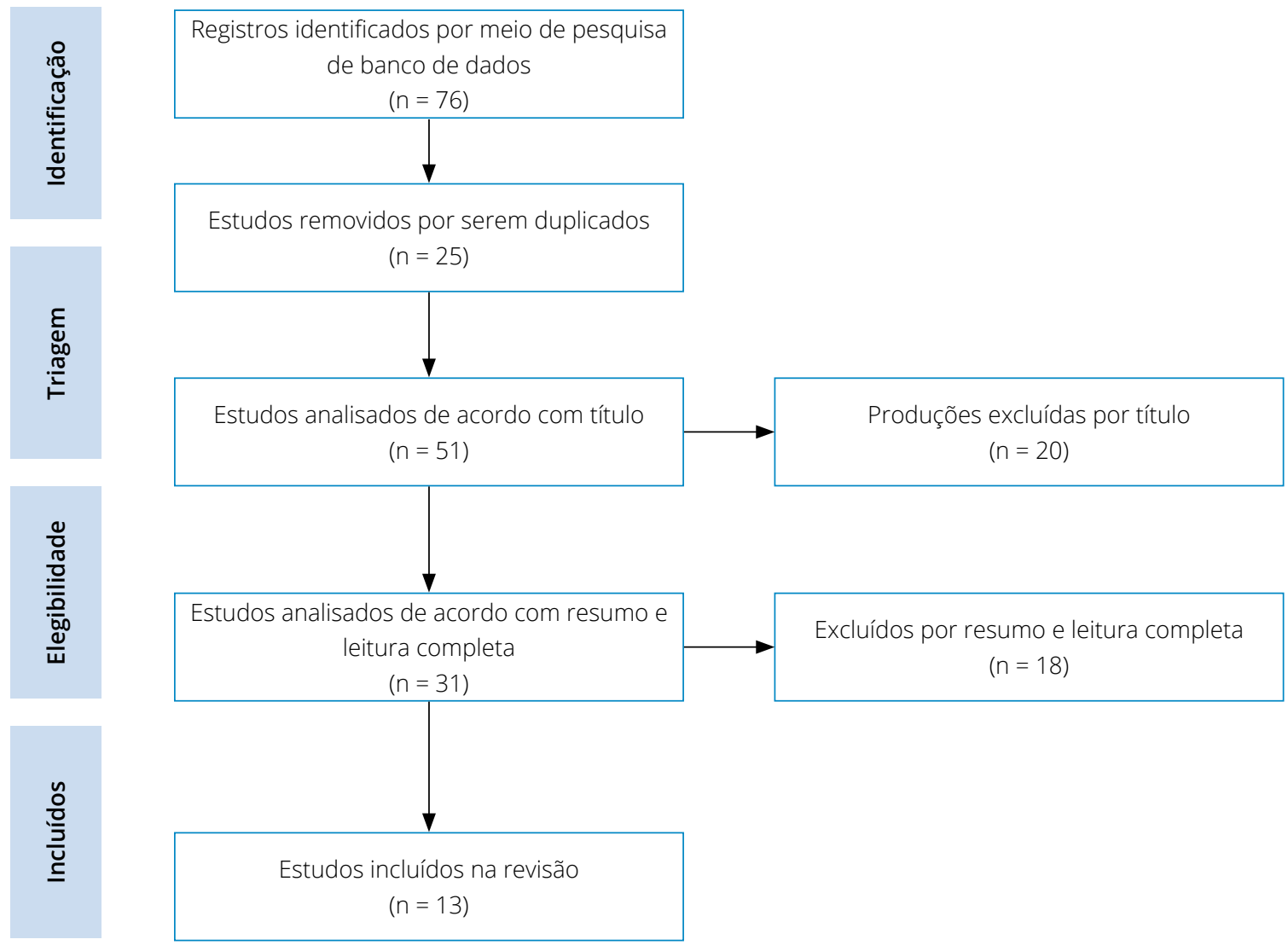

Figura 1. Organograma de seleção dos artigos. Vitória (ES) - 2020. 
Com o intuito de minimizar prováveis erros ou vieses, a seleção foi realizada por dois revisores, de forma independente e organizada em duas etapas. Na primeira etapa, realizou-se a leitura de título e resumo, e na segunda, fez-se a leitura do texto completo. Nos casos em que ocorreram desacordos, houve discussão com a orientadora da pesquisa sobre a inclusão ou exclusão da publicação na revisão (terceiro revisor).

Após a leitura completa das publicações incluídas nesta revisão, essas foram sumarizadas em um documento da Microsoft Word Office 365, contendo: ano de publicação, nome(s) do(s) autor(es), título da publicação, tipo da pesquisa, idioma, quantidade de participantes do estudo, classificação e breve resumo sobre o conteúdo do artigo, sendo o passo número 4.

\section{RESULTADOS}

A síntese dos achados foi organizada e dividida de acordo com os tipos etiológicos das lesões estudas nos artigos, sendo sítio cirúrgico, feridas sem etiologia definida e feridas em pacientes pediátricos, demonstrados sequencialmente na Tabela 1, Tabela 2 e Tabela 3. Já a análise crítica do material levantado possibilitou o agrupamento dos resultados por similaridade semântica, levando a caracterização dos artigos em dois grupos: A) Prevenção e tratamento de infecção em feridas e B) Prevenção de infecção de sítio cirúrgico.

De acordo com a caracterização supracitada, notou-se que 4 produções (30,76\%) foram agrupadas no grupo de prevenção de infecção de sítio cirúrgico e 9 artigos $(69,23 \%)$ agrupados em prevenção e tratamento de infecção em feridas.

Outrossim, notou-se importante relevância nas produções que abordavam pacientes pediátricos, totalizando 2 produções (15,38\%). Em relação ao ano de publicação, 3 delas foram no ano de 2019 (23,1\%), 3 no ano de 2017 (23,1\%), 3 no ano de 2012 (23,1\%), 2 no ano de 2016 (15,4\%), 1 no ano de 2018 (7,7\%) e 1 ano de 2020 (7,7\%). Ademais, com base na análise do perfil de idiomas encontrados, notou-se que todas as produções foram publicadas em inglês.

Tabela 1. Sumarização dos artigos selecionados sobre feridas cirúrgicas. Vitória (ES) - 2020.

\begin{tabular}{|c|c|c|c|c|c|}
\hline Título & $\begin{array}{l}\text { Categoria e Ferida } \\
\text { Estudada }\end{array}$ & $\begin{array}{l}\text { Autor/ } \\
\text { Ano }\end{array}$ & Tipo de Estudo & Idioma & Breve Conclusão \\
\hline $\begin{array}{l}\text { Dialkylcarbamoyl chloride } \\
\text { dressings in the prevention of } \\
\text { surgical site infections after } \\
\text { nonimplant vascular surgery. }\end{array}$ & $\begin{array}{c}\text { Prevenção de } \\
\text { infecção de sítio } \\
\text { cirúrgicolSítio } \\
\text { cirúrgico de implante } \\
\text { vascular }\end{array}$ & $\begin{array}{c}\text { Bua N } \\
\text { et al., } 2017\end{array}$ & $\begin{array}{c}\text { Estudo } \\
\text { prospectivo, } \\
\text { comparativo e não } \\
\text { randomizado com } \\
200 \text { participantes. }\end{array}$ & Inglês & $\begin{array}{c}\text { Possui efeitos na prevenção } \\
\text { de infecção de sítio cirúrgico } \\
\text { em vários grupos de } \\
\text { pacientes diferentes e pode } \\
\text { ter um papel significativo no } \\
\text { futuro tratamento de feridas } \\
\text { cirúrgicas. }\end{array}$ \\
\hline $\begin{array}{l}\text { Reducing SSI rates for women } \\
\text { birthing by caesarean section. }\end{array}$ & $\begin{array}{c}\text { Prevenção de } \\
\text { infecção de sítio } \\
\text { cirúrgicolsítio } \\
\text { cirúrgico de cesárea }\end{array}$ & $\begin{array}{c}\text { Taylor L } \\
\text { et al., } 2016\end{array}$ & $\begin{array}{l}\text { Estudo de caso } \\
\text { multifacetado } \\
\text { sem informação } \\
\text { da quantidade de } \\
\text { participantes. }\end{array}$ & Inglês & $\begin{array}{l}\text { Queda da incidência de } \\
\text { infecção de sítio cirúrgico } \\
\text { em mulheres após a } \\
\text { cesárea e promoção de } \\
\text { redução de custos. }\end{array}$ \\
\hline $\begin{array}{l}\text { A pilot feasibility randomised } \\
\text { clinical trial comparing } \\
\text { dialkylcarbamoylchloride-coated } \\
\text { dressings versus standard care for } \\
\text { the primary prevention of surgical } \\
\text { site infection. }\end{array}$ & $\begin{array}{c}\text { Prevenção de } \\
\text { infecção em sítio } \\
\text { cirúrgico\Feridas } \\
\text { incisionais fechadas }\end{array}$ & $\begin{array}{l}\text { Totty JP. } \\
\text { et al., } 2019\end{array}$ & $\begin{array}{l}\text { Ensaio clínico } \\
\text { randomizado } \\
\text { de viabilidade } \\
\text { piloto com } 114 \\
\text { pacientes. }\end{array}$ & Inglês & $\begin{array}{c}\text { Não apresentou reações } \\
\text { adversas, sendo considerado } \\
\text { tolerável, eficaz e de } \\
\text { custo-benefício adequado. }\end{array}$ \\
\hline $\begin{array}{l}\text { Prospective cohort study on } \\
\text { surgical wounds comparing } \\
\text { a polyhexanide-containing } \\
\text { biocellulose dressing with a dialkyl- } \\
\text { carbamoyl-chloride-containing } \\
\text { hydrophobic dressing. }\end{array}$ & $\begin{array}{c}\text { Prevenção de } \\
\text { infecção em } \\
\text { sítio cirúrgicol } \\
\text { Feridas cirúrgicas } \\
\text { cicatrizadas por } 2^{a} \\
\text { intenção }\end{array}$ & $\begin{array}{c}\text { Nilsen AM e } \\
\text { Andriessen } \\
\text { A, } 2012\end{array}$ & $\begin{array}{l}\text { Estudo de coorte } \\
\text { prospectivo com } \\
60 \text { pacientes. }\end{array}$ & Inglês & $\begin{array}{l}\text { Apontou melhora do sítio } \\
\text { cirúrgico e não houve } \\
\text { melhora das taxas álgicas. }\end{array}$ \\
\hline $\begin{array}{l}\text { Dialkylcarbamoyl chloride- } \\
\text { coated versus alginate dressings } \\
\text { after pilonidal sinus excision: } \\
\text { a randomized clinical trial } \\
\text { (SORKYSA study). }\end{array}$ & $\begin{array}{c}\text { Prevenção e } \\
\text { tratamento de } \\
\text { infecção em feridas } \\
\text { Ferida cirúrgica } \\
\text { por excisão de seio } \\
\text { pilonidal }\end{array}$ & $\begin{array}{l}\text { Romain B. et } \\
\text { al., } 2020\end{array}$ & $\begin{array}{c}\text { Estudo } \\
\text { multicêntrico } \\
\text { randomizado com } \\
246 \text { pacientes. }\end{array}$ & Inglês & $\begin{array}{c}\text { O número de lesões } \\
\text { totalmente curadas em } \\
75 \text { dias foi significativamente } \\
\text { maior na comparação } \\
\text { com alginato. }\end{array}$ \\
\hline
\end{tabular}


Tabela 2. Sumarização dos artigos selecionados sem etiologia definida. Vitória (ES) - 2020.

\begin{tabular}{|c|c|c|c|c|c|}
\hline Título & $\begin{array}{c}\text { Categoria e Ferida } \\
\text { Estudada }\end{array}$ & $\begin{array}{l}\text { Autor/ } \\
\text { Ano }\end{array}$ & Tipo de Estudo & Idioma & Breve Conclusão \\
\hline $\begin{array}{l}\text { Dialkylcarbamoyl chloride } \\
\text { (DACC)-coated dressings in the } \\
\text { management and prevention of } \\
\text { wound infection: a systematic } \\
\text { review. }\end{array}$ & $\begin{array}{c}\text { Prevenção e } \\
\text { tratamento de } \\
\text { feridas infectadası } \\
\text { Sem delimitação } \\
\text { específica da } \\
\text { etiologia da lesão }\end{array}$ & $\begin{array}{l}\text { Totty J.P } \\
\text { et al., } 2017\end{array}$ & $\begin{array}{c}\text { Revisão } \\
\text { Sistemática }\end{array}$ & Inglês & $\begin{array}{l}\text { É encorajado o uso na } \\
\text { prevenção e tratamento de } \\
\text { feridas infectadas por não } \\
\text { haver efeitos adversos. }\end{array}$ \\
\hline $\begin{array}{l}\text { Infection management: The } \\
\text { use of DACC-coated dressings } \\
\text { in the management of wound } \\
\text { infection. }\end{array}$ & $\begin{array}{l}\text { Prevenção e } \\
\text { tratamento de } \\
\text { feridas infectadası } \\
\text { Sem delimitação } \\
\text { específica da } \\
\text { etiologia da lesão }\end{array}$ & $\begin{array}{l}\text { Meuleneire } \\
\text { F, } 2017\end{array}$ & $\begin{array}{l}\text { Revisão de } \\
\text { Literatura }\end{array}$ & Inglês & $\begin{array}{c}\text { O uso demonstrou } \\
\text { capacidade de gerir a } \\
\text { biocarga em diferentes tipos } \\
\text { de feridas, incluindo em } \\
\text { lesões complexas, impedindo } \\
\text { que haja uma deterioração } \\
\text { do quadro da lesão e } \\
\text { resultando em cura. }\end{array}$ \\
\hline $\begin{array}{l}\text { Bacterial-binding dressings in the } \\
\text { management of wound healing } \\
\text { and infection prevention: a } \\
\text { narrative review. }\end{array}$ & $\begin{array}{c}\text { Prevenção e } \\
\text { tratamento de } \\
\text { feridas infectadas } \\
\text { Sem delimitação } \\
\text { específica da } \\
\text { etiologia da lesão }\end{array}$ & $\begin{array}{l}\text { Chadwick P. } \\
\text { e Ousey K, } \\
2019\end{array}$ & $\begin{array}{l}\text { Revisão de } \\
\text { Literatura }\end{array}$ & Inglês & $\begin{array}{l}\text { O uso promove maior } \\
\text { benefício na profilaxia } \\
\text { e redução da biocarga } \\
\text { bacteriana. }\end{array}$ \\
\hline $\begin{array}{l}\text { A comparison between DACC } \\
\text { with chlorhexidine acetate- } \\
\text { soaked paraffin gauze and foam } \\
\text { dressing for skin graft donor } \\
\text { sites. }\end{array}$ & $\begin{array}{c}\text { Prevenção e } \\
\text { tratamento de } \\
\text { feridas infectadas } \\
\text { Sem delimitação } \\
\text { específica da } \\
\text { etiologia da lesão }\end{array}$ & $\begin{array}{l}\text { Lee J.W. } \\
\text { et al., } 2018\end{array}$ & $\begin{array}{l}\text { Estudo } \\
\text { retrospectivo com } \\
60 \text { pacientes. }\end{array}$ & Inglês & $\begin{array}{l}\text { O uso associado à gaze } \\
\text { de parafina embebida } \\
\text { em clorexidina em áreas } \\
\text { doadoras de enxerto de } \\
\text { pele, diminuiu o tempo de } \\
\text { cicatrização e sendo eficaz } \\
\text { em lesões infectadas. }\end{array}$ \\
\hline $\begin{array}{l}\text { Using Cutimed® Sorbact } ® \\
\text { Hydroactive on chronic infected } \\
\text { wounds. }\end{array}$ & $\begin{array}{c}\text { Prevenção e } \\
\text { tratamento de } \\
\text { feridas infectadas } \\
\text { Sem delimitação } \\
\text { específica da } \\
\text { etiologia da lesão }\end{array}$ & $\begin{array}{c}\text { Bruce Z, } \\
2012\end{array}$ & $\begin{array}{l}\text { Estudo clínico } \\
\text { multicêntrico sem } \\
\text { informação da } \\
\text { quantidade de } \\
\text { participantes. }\end{array}$ & Inglês & $\begin{array}{c}\text { Houve melhora da lesão e } \\
\text { dos sintomas, principalmente } \\
\text { quando usadas em lesões } \\
\text { crônicas. }\end{array}$ \\
\hline $\begin{array}{l}\text { Clinical efficacy of } \\
\text { dialkylcarbamoylchloride-coated } \\
\text { cotton acetate dressing versus } \\
\text { combination of normal saline } \\
\text { dressing and } 2 \% \text { mupirocin } \\
\text { ointment in infected wounds of } \\
\text { epidermolysis bullosa. }\end{array}$ & $\begin{array}{c}\text { Prevenção e } \\
\text { tratamento de } \\
\text { feridas infectadas } \\
\text { Epidermólise } \\
\text { bolhosa }\end{array}$ & $\begin{array}{l}\text { Dwiyana RF } \\
\text { et al., } 2019\end{array}$ & $\begin{array}{l}\text { Ensaio clínico- } \\
\text { cego randomizado } \\
\text { com } 14 \text { pacientes. }\end{array}$ & Inglês & $\begin{array}{l}\text { Promoveu fechamento mais } \\
\text { rápido da ferida e foi tão } \\
\text { eficaz quanto a combinação } \\
\text { de curativo com solução } \\
\text { salina normal e pomada de } \\
\text { mupirocina a } 2 \% \text {. }\end{array}$ \\
\hline
\end{tabular}

Tabela 3. Sumarização dos artigos selecionados sobre feridas pediátricas. Vitória (ES) - 2020.

\begin{tabular}{|c|c|c|c|c|c|}
\hline Título & $\begin{array}{c}\text { Categoria e Ferida } \\
\text { Estudada }\end{array}$ & $\begin{array}{l}\text { Autor/ } \\
\text { Ano }\end{array}$ & Tipo de Estudo & Idioma & Breve Conclusão \\
\hline $\begin{array}{l}\text { Infection management: } \\
\text { Antimicrobial management } \\
\text { for children with epidermolysis } \\
\text { bullosa. }\end{array}$ & $\begin{array}{c}\text { Prevenção e } \\
\text { tratamento de } \\
\text { feridas infectadas } \\
\text { Epidermólise } \\
\text { bolhosa pediátrica }\end{array}$ & $\begin{array}{c}\text { Denyer J, } \\
2012\end{array}$ & $\begin{array}{l}\text { Revisão de } \\
\text { Literatura }\end{array}$ & Inglês & $\begin{array}{c}\text { Melhorou o aspecto } \\
\text { das lesões e promoveu } \\
\text { diminuição da carga } \\
\text { bacteriana. }\end{array}$ \\
\hline $\begin{array}{l}\text { Efficacy of } \\
\text { Dialkylcarbamoylchloride-Coated } \\
\text { Dressing in Management of } \\
\text { colonize for Infected Neonatal } \\
\text { and Pediatric Wounds. }\end{array}$ & $\begin{array}{c}\text { Prevenção e } \\
\text { tratamento de } \\
\text { feridas infectadas } \\
\text { Sem delimitação } \\
\text { específica da } \\
\text { etiologia da lesão na } \\
\text { pediatria }\end{array}$ & $\begin{array}{l}\text { Boyar V, } \\
2016\end{array}$ & $\begin{array}{l}\text { Revisão } \\
\text { Sistemática }\end{array}$ & Inglês & $\begin{array}{c}\text { Promoveu atividade } \\
\text { bacteriostática sem criar } \\
\text { citotoxicidade ou resposta } \\
\text { inflamatória. A lesão foi } \\
\text { cicatrizada entre } \\
2 \text { e } 4 \text { semanas. }\end{array}$ \\
\hline
\end{tabular}




\section{DISCUSSÃO}

A avaliação criteriosa da ferida, considerando não somente a lesão, mas também o estado geral do paciente e aspectos relacionados ao ambiente e ao acesso a serviços de saúde são fundamentais para o sucesso do tratamento instituído.

A carga microbiana das feridas é tema de discussão há muitos anos. Nos dias atuais essa temática vem avançando à medida que os microrganismos se mostram mais resistentes às terapias com antibióticos tópicos e/ou sistêmicos. Tendo em vista o uso excessivo de antibióticos e a falta de evidências que apoiem sua eficácia clínica em feridas crônicas que não cicatrizam, há a necessidade de desenvolver terapias para superar as barreiras atuais de cura no tratamento de feridas causadas pela ineficácia dos antibióticos em infecções de lesões resistentes a antimicrobianos ${ }^{8-11}$. $\mathrm{O}$ uso de antibióticos sistêmicos, ainda assim, é recomendado para infecções profundas ou sistêmicas, podendo melhorar a cicatrização de feridas quando indicado de maneira adequada ${ }^{8-10}$.

No que tange à terapêutica antimicrobiana tópica clássica com o uso de produtos com antibióticos, como pomadas, sprays e afins, apesar de terem alguma atuação direta nas bactérias da ferida, também há a possibilidade de resistência bacteriana, além de indução a reações de hipersensibilidade e superinfecções ${ }^{8,9}$.

Considerando terapias com baixo risco de gerar resistência microbiana, novos produtos vêm sendo desenvolvidos para tratamento tópico das feridas, com o objetivo de promover a interrupção do processo de adesão inicial dos microrganismos ao leito da lesão, dentre esses, destaca-se o DACC, um derivado de ácido graxo que age como antibacteriano passivo, de modo a sequestrar a bactéria para dentro do curativo por meio de ligações hidrofóbicas da superfície extracelular do microrganismo, promovendo aderência irreversivel ao substrato do DACC ${ }^{12-14}$.

A partir da análise dos resultados, observa-se um consenso em relação aos benefícios do uso de DACC para o manejo de biofilmes em feridas. Ademais, sua utilização pode acelerar o processo cicatricial quando comparado à utilização de alginato, e pode ser usado como cobertura profilática ao desenvolvimento de infecção ${ }^{14}$.

O DACC demonstrou, in vitro, a capacidade de se ligar a diversos microrganismos patológicos, incluindo Pseudomonas aeruginosa e Staphylococcus aureus resistente à meticilina (MRSA), possuindo efeito bactericida e bacteriostática ${ }^{5}$. Além disso, evidências demonstram que o produto fornece atividade bacteriostática, contudo, sem gerar citotoxicidade, sendo considerada uma via alternativa e acessível para a cicatrização de lesões infectadas ou contaminadas com grande quantidade de biofilme ${ }^{12,15}$.

Outro aspecto interessante é a versatilidade das coberturas com DACC. Os estudos evidenciam seu uso em diversas situações, uma delas no pós-cirúrgico de excisão do seio pilonidal, a qual é considerada uma condição comum que afeta adultos jovens, sendo caracterizada pelo surgimento de folículos pilosos na fenda natal da área sacrococcígea, gerando infecção, desconforto e queixas álgicas, em que as opções de tratamento se resumem em excisão cirúrgica com cicatrização por segunda intençãa ${ }^{16}$. Estudos como o SOKYSA study (2020) demonstram a efetividade do uso de DACC em lesões infectadas, especialmente após a excisão do seio pilonidal. No estudo supracitado, o DACC foi comparado ao uso de alginato após a excisão. Durante o acompanhamento dermatológico, as lesões com cobertura de alginato demonstraram maior quantidade de esfacelo quando comparadas às lesões revestidas com DACC, já em relação à cicatrização, o grupo com DACC obteve maior sucesso, evoluindo para cicatrização em até 75 dias $^{14}$.

Outra utilização do DACC é como cobertura profilática. Um estudo prospectivo, não randomizado e comparativo, em um centro de cirurgia vascular, com 200 participantes que receberam curativos revestidos com DACC, apontou melhora evidente do número de pacientes com sítio cirúrgico infectado em uso de coberturas com DACC quando comparada com a terapia convencional ${ }^{17}$.

Outra indicação descrita foi em casos de epidermólise bolhosa, sendo comparado ao tratamento de solução salina e correlatos de mupirocina a $2 \%$, demonstrando uma melhora equivalente à terapia antimicrobiana tradicional, sendo possivelmente considerada uma alternativa aos pacientes que possuem reações adversas ao uso de mupirocina a $2 \%$, visto que o DACC não possui reações secundárias conhecidas ${ }^{18}$.

Corroborando o estudo de Dwiyana (2019), um grupo de pesquisadores, em 2012, avaliou o perfil quantitativo da biocarga bacteriana em pacientes com lesões provocadas por epidermólise bolhosa, em que apresentou uma narrativa permissiva do uso de DACC por um longo período, afirmando que há atenuação dos sintomas de intensa colonização, como odor, queixas álgicas e exsudação, além disso, beneficiando a gerência profilática do biofilme da ferida ${ }^{19}$. 
Outrossim, o uso de DACC em lesões complexas tem sido aconselhado, visto que os patógenos não são destruídos, mas armazenados, não havendo risco de acúmulo de detritos celulares na lesão, o que poderia levar à um exacerbamento da resposta inflamatória local, levando à dor e disfunção do reparo tissular ${ }^{5,18,19}$, e diante das evidências descritas das coberturas com DACC não possuírem efeitos adversos, tornam-se opções viáveis para lesões crônicas, agudas e, principalmente, infectadas ${ }^{12}$.

Em um estudo multicêntrico conduzido na Inglaterra e Irlanda, buscou-se avaliar a evolução das lesões de pele em âmbitos de eritema, edema, dor, odor e exsudato, sendo usado em uma variedade de pacientes com lesões dicótomas, como úlceras venosas, lesões traumáticas e úlcera mista. Seu desfecho apontou uma queda no número de lesões com sinais de inflamação (79\% para 29\%), além de aumento de números de lesões com tecidos epiteliais e tecidos de granulação em pacientes em uso de coberturas com DACC ${ }^{20}$.

O uso de DACC com a gaze de parafina embebida com acetato de clorexidina em locais de doação de enxerto pele apontou características contributivas para a cicatrização, reduzindo o tempo cicatricial, sendo eficaz e recomendado no tratamento de feridas infectadas ${ }^{21}$.

No Brasil, estão disponíveis coberturas impregnadas com DACC em forma de swabs, indicados para desbridamento mecânico e remoção do biofilme, em forma de compressa e impregnado nos curativos multicamadas com borda de silicone ${ }^{3}$.

Com o avanço tecnológico e aumento do arsenal de tecnologias para tratamento de feridas, é fundamental que os profissionais da saúde, em especial os enfermeiros, tenham conhecimento sobre a aplicabilidade das diversas coberturas e os possíveis resultados esperados, a fim de que o gerenciamento de lesões cutâneas, especialmente as de maior complexidade, possa ser realizado de forma assertiva e considerando custo-efetividade.

\section{CONCLUSÃO}

Identificou-se que o DACC foi capaz de promover ações benéficas no que se refere ao tratamento de feridas, especialmente as de maior complexidade. Destaca-se seu papel no gerenciamento microbiano, seja para prevenção de infecção do sítio cirúrgico, seja para tratamento de feridas infectadas ou com biofilme.

A escolha adequada das coberturas e dos curativos pode contribuir com a utilização mais racional das tecnologias existentes e dos antibióticos (tão controverso na prática clínica), culminando em redução de custos para o sistema de saúde e promovendo mais qualidade de vida aos indivíduos que sofrem com feridas crônicas.

Salienta-se a limitação na quantidade de pesquisas publicadas sobre a temática, com estudos com número limitado de participantes. Dessa forma, é de extrema relevância a realização de novas investigações que ampliem a utilização dessa tecnologia para outros tipos de feridas e considere o seu custo-benefício e aplicabilidade.

\section{CONTRIBUIÇÃO DOS AUTORES}

Conceitualização: Freitas PSS e Ramalho AO; Metodologia: Rezende LDA, Freitas PSS, Ramalho AO; Investigação: Rezende LDA e Silva KEJ; Redação - Primeira versão: Rezende LDA e Silva KEJ. Redação-Revisão \& Edição: Santos RA, Freitas PSS, Ramalho AO, Fiorin BH e Santos RA; Supervisão: Freitas PSS e Ramalho AO.

\section{DISPONIBILIDADE DE DADOS DE PESQUISA}

Dados serão disponibilizados mediante pedido.

\section{REFERÊNCIAS}

1. Malone M, Bjarnsholt T, McBain AJ, James GA, Stoodley P, Leaper D et al. The prevalence of biofilms in chronic wounds: a systematic review and meta-analysis of published data. J Wound Care. 2017;26(1):20-5. https://doi.org/10.12968/ jowc.2017.26.1.20 
2. Murphy C, Atkin L, Swanson T, Tachi M, Tan YK, Vega M et al. Consensus Document. Abordar feridas de difícil cicatrização com uma estratégia de intervenção precoce antibiofilme: higienização da ferida. J Wound Care 2020;29(Suppl3b):s1-s28. Disponível em: https://www.woundhygiene.com/media/bs3bxuod/portugal_jwc_convatec_wound-hygiene-28pp_14-feb_ca-por.pdf

3. Jones CM, Rothermel AT, Mackay DR. Evidence-Based Medicine: Wound Management. Plast Reconstr Surg. 2017;140(1):201e-216e. https://doi.org/10.1097/PRS.0000000000003486

4. Viviana SGC, Thum M, Aline OR, Beloto Silva O, Franco Coelho M, Medeiros da Silva Queiroz W et al. Analysis of "1st Brazilian Recommendation for Biofilm Management in Chronic and Complex Wounds." ESTIMA, BrazJ Enterostomal Ther. 2019;17:e1819. https://doi.org/https://doi.org/10.30886/estima.v17.783_IN

5. Totty JP, Hitchman LH, Cai PL, Harwood AE, Wallace T, Carradice D et al. A pilot feasibility randomised clinical trial comparing dialkylcarbamoylchloride-coated dressings versus standard care for the primary prevention of surgical site infection. Int Wound J. 2019;16(4):883-90. https://doi.org/10.1111/iwj.13113

6. Botelho LLR, Cunha CC de A, Macedo M. O Método Da Revisão Integrativa Nos Estudos Organizacionais. Gestão e Sociedade. 2011;5(11):121-136. https://doi.org/10.21171/ges.v5i11.1220

7. Galvão TF, Pereira MG. Revisões sistemáticas da literatura: passos para sua elaboração. Epidemiol e Servi Saúde. 2014;23(1):1834. http://doi.org/10.5123/S1679-49742014000100018

8. Pinto AM, Cerqueira MA, Bañobre-Lópes M, Pastrana LM, Sillankorva S. Bacteriophages for Chronic Wound Treatment: from Traditional to Novel Delivery Systems. Viruses. 2020;12(2):235. https://doi.org/10.3390/v12020235

9. Powers JG, Higham C, Broussard K, Phillips TJ. Wound healing and treating wounds: Chronic wound care and management. J Am Acad Dermatol. 2016;74(4):607-25. https://doi.org/10.1016/j.jaad.2015.08.070

10. Bowler PG. Antibiotic resistance and biofilm tolerance: a combined threat in the treatment of chronic infections. J Wound Care. 2018;27(5):273-7. https://doi.org/10.12968/jowc.2018.27.5.273

11. Pieper B, Sobeck J, Kaljee L, Templin TN. A Descriptive Study Using an Intercept Survey: Knowledge, Attitudes, Beliefs, and Behaviors About Systemic Antibiotic Use in Adults Who Reported a Wound Within the Previous Year. J Wound Ostomy Continence Nurs. 2020;47(1):20-5. https://doi.org/10.1097/WON.0000000000000612

12. Meuleneire F. Infection management: The use of DACC-coated dressings in the management of wound infection. Br J Nurs. 2012;21(Sup2):4-7. https://doi.org/10.12968/bjon.2012.21.Sup2.4

13. Chadwick P, Ousey K. Bacterial-binding dressings in the management of wound healing and infection prevention: a narrative review. J Wound Care. 2019;28(6):370-82. https://doi.org/10.12968/jowc.2019.28.6.370

14. Romain B, Mielcarek M, Delhorme JB, Meyer N, Brigand C, Rohr S et al. Dialkylcarbamoyl chloride-coated versus alginate dressings after pilonidal sinus excision: a randomized clinical trial (SORKYSA study). BJS open. 2020;4(2):225-31. https://doi. org/10.1002/bjs5.50259

15. Boyar V. Efficacy of dialkylcarbamoylchloride-coated dressing in management of colonized or infected neonatal and pediatric wounds. J Wound Ostomy Continence Nurs. 2016;43(5):547-50. https://doi.org/10.1097/WON.0000000000000266

16. Biter LU, Beck GMN, Mannaerts GHH, Stok MM, Ham AC, Grotenhuis BA. The use of negative-pressure wound therapy in pilonidal sinus disease: a randomized controlled trial comparing negative-pressure wound therapy versus standard open wound care after surgical excision. Dis Colon Rectum. 2014;57(12):1406-11. https://doi.org/10.1097/DCR.0000000000000240

17. Bua N, Smith GE, Totty JP, Pan D, Wallace T, Carradice D et al. Dialkylcarbamoyl Chloride Dressings in the Prevention of Surgical Site Infections after Nonimplant Vascular Surgery. Ann Vasc Surg. 2017;44:387-92. https://doi.org/10.1016/j.avsg.2017.03.198

18. Dwiyana RF, Gondokaryono SP, Rahardja JI, Diana IA, Yogya Y, Gunawan H. Clinical efficacy of dialkylcarbamoylchloride-coated cotton acetate dressing versus combination of normal saline dressing and $2 \%$ mupirocin ointment in infected wounds of epidermolysis bullosa. Dermatol Ther. 2019;32(5):e13047. https://doi.org/10.1111/dth.13047

19. Denyer J. Infection management: Antimicrobial management for children with epidermolysis bullosa. Br J Nurs. 2012;21(Sup2):810. https://doi.org/10.12968/bjon.2012.21.Sup2.8

20. Bruce Z. Using Cutimed $®$ Sorbact ${ }^{\circledR}$ hydroactive on chronic infected wounds. Wounds UK. 2012;8(1):119-29. Disponível em: https://www.researchgate.net/publication/286986985_Using_CutimedR_SorbactR_hydroactive_on_chronic_infected_wounds

21. Lee JW, Park SH, Suh IS, Jeong HS. A comparison between DACC with chlorhexidine acetate-soaked paraffin gauze and foam dressing for skin graft donor sites. J Wound Care. 2018;27(1):28-35. https://doi.org/10.12968/jowc.2018.27.1.28 